cC) (7) \&

\title{
Cursos de Licenciatura na modalidade da EAD nas IES públicas e privadas (2015-2019): número de matrículas e de polos
}

\author{
Henaldo Barros Moraes \\ Centro Universitário de Patos de Minas - UNIPAM, Brasil \\ José Carlos Souza Araújo \\ Universidade de Uberaba - UNIUBE, Brasil
}

\begin{abstract}
RESUMO
O presente artigo apresenta um estudo a respeito da expansão experimentada quanto ao número de matrículas e de polos em cursos de Licenciatura, na modalidade da EAD. Para obter os dados a respeito, foram analisadas as Sinopses Estatísticas do Ensino Superior, fornecidas pelo MEC, no período de 2015 a 2019, bem como artigos disponíveis na internet. Os cursos de Licenciatura em EAD vêm passando por um processo de expansão acentuada nos últimos anos, em vista de uma forte tendência de interiorização e democratização promovidas pelas instituições de educação superior (IES), principalmente, as privadas. Atualmente, poucos trabalhos científicos focalizam a referida expansão. Os resultados apresentados mostram o crescimento dos cursos de Licenciatura, analisando as variações sofridas pelo número de matrículas e pela expansão de polos no referido período.
\end{abstract}

PALAVRAS-CHAVE: Educação a Distância. Educação Superior. Formação de Professores. Licenciatura.

\section{TEACHER TRAINING COURSES IN EAD MODALITY IN PUBLIC AND PRIVATE SCHOOLS (2015 - 2019): NUMBER OF ENROLLMENTS AND POLES}

\begin{abstract}
This article presents a study about the expansion experienced in the number of enrollments and poles in undergraduate courses, in the distance learning modality. To obtain the data, the Higher Education Statistical Synopses, provided by MEC, from 2015 to 2019, as well as articles available on the internet, were analyzed. Undergraduate courses in distance education have been undergoing a process of marked expansion in recent years, in view of a strong trend towards internalization and democratization promoted by higher education institutions especially private ones. Currently, few scientific studies focus on this expansion. The results presented show the growth of the teacher training courses, analyzing the variations suffered by the number of enrollments and the expansion of centers in the referred period.
\end{abstract}

KEY WORDS: Distance Education. College education. Teacher training. Graduation. 


\section{CURSOS DE LICENCIA EN MODALIDAD EAD EN ESCUELAS PÚBLICAS Y PRIVADAS (2015 - 2019): NÚMERO DE INSCRIPCIONES Y POLOS}

\section{RESUMEN}

Este artículo presenta un estudio sobre la expansión experimentada en el número de matrículas y polos en los cursos de pregrado, en la modalidad de educación a distancia. Para la obtención de los datos se analizaron las Sinopsis Estadísticas de Educación Superior, proporcionadas por el MEC, de 2015 a 2019, así como los artículos disponibles en internet. Los cursos de grado en educación a distancia han experimentado un proceso de marcada expansión en los últimos años, ante una fuerte tendencia a la internalización y democratización impulsada por las instituciones de educación superior (IES), especialmente las privadas. Actualmente, pocos trabajos científicos se centran en esta expansión. Los resultados presentados muestran el crecimiento de los cursos de Licenciatura, analizando las variaciones sufridas por el número de matrículas y la expansión de centros en el referido período.

PALABRAS CLAVE: Educación a distancia. Educación universitaria. Formación de profesores. Graduación.

\section{INTRODUÇÃO}

A Educação a Distância (EAD) praticada atualmente não se refere a um modelo novo, inovador ou diferente. Na realidade, o que diferencia a EAD presentemente, em relação aos modelos utilizados no início do século XX, são os meios atuais e inovadores de disponibilização de conteúdos.

A EAD apresenta algumas similaridades com o ensino presencial utilizado nas IES, mas o marco que mais distingue a modalidade da EAD consiste na midiatização do contato entre aluno e professor. Nesse caso, nota-se que existe, neste cenário, a substituição da prática presencial, por parte do aluno em sala de aula, por uma nova proposta, pela qual os alunos buscam a aprendizagem sem estarem no mesmo ambiente físico de estudo, além de serem intermediados através de tecnologias digitais de informação e comunicação (TDIC) ${ }^{1}$ (LITWIN, 2001).

Nesse sentido, nota-se que como forma primordial de ensino, na modalidade da EAD, não existe o contato direto entre aluno e professor fisicamente em sala de aula, mas sim uma ação conjunta de diversos recursos didáticos e de apoio sistemático de uma organização e tutoria. Isto faz com que exista uma nova metodologia de ensino e aprendizagem totalmente independente e flexível aos alunos.

\footnotetext{
${ }^{1}$ Referem-se à tecnologia e à escrita digitais, centrada em uma informação discreta que, em última instância, pode ser representada por 0 (zero) ou 1 (um). 
A EAD é uma modalidade de ensino que apresenta características estritamente específicas, com maneiras próprias de criar um espaço para gerar oportunidades, pelas quais os alunos podem desenvolver seus conhecimentos através das situações implementadas. Esta modalidade é uma forma organizada de estudo, que permite ao aluno se organizar através de materiais de estudos disponibilizados durante todo o decorrer do curso (CARMO, 1997).

O mesmo autor pondera que a EAD não pode ser vista como um modelo de ensino que facilita a obtenção de um título, ou muito menos um ensino de baixa qualidade posto que, na realidade, se trata de uma modalidade que veio para atender um público diferenciado e específico ${ }^{2}$.

De acordo com Carmo (1997) ainda, não é correto afirmar que a EAD surgiu para resolver problemas educacionais que necessitam de resultados rápidos, ou até mesmo que tenha sido criado para solucionar sistemas de ensino fracassados. O mesmo autor posiciona-se que a tendência não é atender demanda de mercado, ou de grupos com idade específica, mas assumir funções de importância bastante significativa no ensino para atender a população adulta. Nesse caso, inclui a educação superior existente e todos os cursos de formação continuada.

Rúbio (2011) postula que a EAD surgiu basicamente diante de uma necessidade social em prover educação, de qualidade, para uma parcela significativa da população que possui o desejo em frequentar um curso superior, e que não é atendida de forma adequada pela modalidade presencial de ensino. Compartilhando o mesmo pensamento, Giolo (2008) advoga que a EAD pode ser considerada um modelo de ensino que possui um papel complementar, ou paralelo, aos programas de ensino presencial.

Atualmente, 2021, os cursos oferecidos na modalidade à distância têm se apresentado como a última ou única oportunidade de estudo para aquelas pessoas que estão envolvidas em longas jornadas de trabalho. Normalmente, estes indivíduos apresentam restrições que impedem a disponibilidade de tempo para a dedicação exclusiva nos estudos presenciais, visto que existe a obrigatoriedade de frequência, e normalmente os professores, nem sempre, estão preparados para atender as necessidades dos alunos adultos (NUNES, 1994).

A EAD, atualmente, oferece benefícios de grande importância para atender uma quantidade enorme de pessoas que busca na educação uma melhoria na qualidade de vida. Trata-se de uma modalidade de educação que apresenta os mesmos benefícios da educação presencial, garantindo qualidade do ensino oferecido e com a capacidade de atender uma grande quantidade de alunos dentro de uma vasta área geográfica.

\footnotetext{
${ }^{2}$ São aquelas pessoas que possuem o perfil para realizarem um curso na modalidade da EAD. Normalmente são pessoas com idade mais avançadas, ou senão aquelas que não dispõem de tempo suficiente para enfrentarem uma sala de aula.
} 
Com relação à qualidade do ensino superior a distância, pode-se dizer que ela é definida através de legislação específica, em documento próprio da Secretaria de Educação a Distância (SEED), que se encontra presente nas Referências de Qualidade para Educação superior, definida na portaria do MEC nº 1 e 2 de 11 de janeiro de 2007 (Brasil, 2007).

\section{A MODALIDADE DA EAD A PARTIR DA LDB 9394/96}

De acordo com Alves (2009), até o final do século XX, a maioria das instituições de educação superior do Brasil não apresentava nenhum tipo de envolvimento com projetos voltados para a implantação de cursos na modalidade de educação a distância. Segundo Maia et al. (2007), a primeira iniciativa de EAD surgiu no país, no ano de 1904, numa publicação do Jornal do Brasil com uma oferta de profissionalização por correspondência para datilógrafo.

A maior parte das universidades brasileiras iniciou os primeiros testes, em cursos em EAD, somente no ano de 1990 com a utilização em massa das TDIC; e, no ano de 1994, houve um impulso muito forte, pois foi o ano de implantação e expansão da rede mundial (internet), dentro do ambiente universitário.

As bases legais com relação à Educação a Distância foram estabelecidas pela LDB, Lei n. ${ }^{\circ}$ 9.394, de 20 de dezembro de 1996, na qual, o artigo 80 inseriu a EAD no Brasil em todos os níveis, evidenciando a importância desta modalidade no contexto da educação nacional e por sua inserção no Plano Nacional de Educação (PNE) (BRASIL, 1996).

O artigo 80 apresenta quatro parágrafos que coloca sub judice o Poder Público, excluindo desta forma a participação da sociedade civil:

O Poder Público incentivará o desenvolvimento e a veiculação de programas de ensino a distância, em todos os níveis e modalidades de ensino e de educação continuada.

$\S 1^{\circ}$ A educação a distância, organizada com abertura e regime especiais, será oferecida por instituições especificamente credenciadas pela União.

$\S 2^{\circ}$ A União regulamentará os requisitos para a realização de exames e registro de diploma relativo a cursos de educação a distância.

$\S 3^{\circ}$ As normas para produção, controle e avaliação de programas de educação a distância e a autorização para sua implementação caberão aos respectivos sistemas de ensino, podendo haver cooperação e integração entre os diferentes sistemas.

$\S 4^{\circ}$ A educação a distância gozará de tratamento diferenciado, que incluirá: I- custos de transmissão reduzidos em canais comerciais de radiodifusão sonora e de sons e imagens;

II- concessão de canais com finalidades exclusivamente educativas (BRASIL, 1996).

Foi através desta lei que ficou estabelecido que, a partir do ano de 1996, todos os 
professores que viessem a ser contratados para ministrar aulas no ensino médio e fundamental, deveriam possuir diploma de educação superior em Licenciatura. Essa exigência aumentou, de forma muito significativa, um movimento em direção à qualificação de professores, que já estavam no exercício da profissão. Isso ocasionou uma procura pela educação a distância como alternativa na oferta de cursos de Licenciatura.

As Disposições Transitórias da LDB trazem referências à EAD, dando ênfase na necessidade de formação de professores, conforme pode ser visto no parágrafo $3^{\circ}$, inciso III:

Art. 87 É instituída a Década da Educação, a iniciar-se um ano a partir da publicação desta Lei.

$\S 1^{\circ}$ A União, no prazo de um ano a partir da publicação desta Lei, encaminhará, ao Congresso Nacional, o Plano Nacional de Educação, com diretrizes e metas para os dez anos seguintes, em sintonia com a Declaração Mundial sobre Educação para Todos.

$\S 3^{\circ} \mathrm{O}$ Distrito Federal, cada Estado e Município, e, supletivamente, a União, devem:

II- prover cursos presenciais ou à distância aos jovens e adultos insuficientemente escolarizados;

III- realizar programas de capacitação para todos os professores em exercício, utilizando também, para isto, os recursos da educação à distância. (BRASIL, 1996).

No parágrafo $1^{\circ}$ existe a indicação do plano nacional de educação que foi elaborado para definir metas da educação para os anos seguintes, universalizando o ensino através da Declaração Mundial sobre Educação. No inciso III do parágrafo $3^{\circ}$ é utilizado o termo “capacitação" para conotar que os profissionais, que estão na ativa, não apresentam capacidade ou qualificação suficiente para exercer o magistério; neste caso, necessitam de uma capacitação no exercício da função utilizando os recursos da EAD para atuarem nas escolas (RÚBIO, 2011).

A respeito da afirmação apresentada no parágrafo anterior, as orientações contidas nos documentos do Banco Mundial sustentam que não é função das escolas fornecer conhecimento técnico e profissional, e que estas podem ser adquiridas no próprio local de trabalho através de treinamento simples. Nesse sentido, é recomendada a modalidade de EAD, por apresentar vantagens com relação aos $\operatorname{custos}^{3}$, se comparado à modalidade presencial, o que implica que a legislação continua seguindo as orientações de um organismo internacional (MOTA, 2009; BARRETO, 2018).

Mota (2009) explica que algumas normas foram lançadas com o objetivo de permitir que as instituições pudessem ofertar cursos na modalidade de EAD, cumprindo algumas prerrogativas que antes eram de responsabilidade da União. Nesse caso, o Decreto n ${ }^{\circ}$ 2.494/98

\footnotetext{
${ }^{3}$ De acordo com Barreto (2018) os custos de manutenção de alunos na EAD se configuram bem menores do que num curso presencial.
} 
MORAES, H. B.; ARAÚJO, J. C. S.

regulamentava o Art. 80 da LDB, e o Decreto n 2.561/98 alterava os artigos 11 e 12 do Decreto $n^{\circ} 2.494 / 98$. Além disso, a portaria n ${ }^{\circ} 301 / 98$ criou as normatizações para o credenciamento das instituições de educação superior no sentido de ofertarem cursos de graduação na modalidade de EAD.

Posteriormente, em abril de 2001, a resolução nº 01 foi editada pelo Conselho Nacional de Educação, quando ficou estabelecida a oferta de cursos de pós-graduação no país, e fixou limites e exigências para o reconhecimento de cursos ofertados por instituições de fora do país na modalidade de EAD. Nesse mesmo ano, o Ministério da Educação e Cultura (MEC) publicou a Portaria $\mathrm{n}^{\circ} 2.253$, a qual estipulou que $20 \%$ da carga horaria máxima de cursos oferecidos por IES, e já reconhecidos, poderiam ser aplicados na modalidade de EAD (BRASIL, 2018a).

A organização a ser seguida pelas instituições de ensino, para estabelecer a consolidação da EAD, está presente no Decreto $\mathrm{n}^{\circ} 5.622 / 05$, o qual estabelece novas regulamentações para o Art. 80 da LDB/1996. No entanto, todas as disposições legais, para as IES públicas e privadas, precisavam ser geridas por um sistema específico, o que foi regulamentado a partir da instituição da Universidade Aberta do Brasil (UAB), através do Decreto nº 5.800/06 (BRASIL, 2005; 2006).

A UAB surgiu após a criação da extinta Secretaria de Educação a Distância (SEED), pelo Ministério da Educação e Cultura, no dia 27 de maio de 1996, com a promulgação do Decreto $\mathrm{n}^{\mathrm{o}}$ 1.917, que, além da UAB, gerou outras ações, tais como, o Proinfo, TV Escola, Proformação, Pro-licenciatura entre outros. Nos primórdios de sua criação, a UAB ficou sobre a responsabilidade da SEED, mas através da Portaria nº 318 do MEC, de 02 de abril de 2009, sua alocação passou para a Coordenação de Aperfeiçoamento de Pessoal de Nível Superior (CAPES), na qual permanece até os dias atuais.

\section{OS NÚMEROS DA EDUCAÇÃO A DISTÂNCIA NO BRASIL}

Nos últimos 10 anos, o número de matrículas nos cursos de Licenciatura vem experimentando um crescimento bastante acentuado. De acordo com dados emitidos pelas Sinopses Estatísticas da Educação Superior, os cursos de Licenciatura vêm passando por um crescimento muito acentuado nos últimos anos. Somente de 2018 para 2019 estes cursos experimentaram um crescimento de 10,43\% no número de matrícula (BRASIL, 2018; 2019).

De acordo com os Censos Escolares da Educação Superior/ Sinopses Estatísticas da Educação Superior (BRASIL, 2019), o número de cursos de Licenciatura, por intermédio da EAD, vem aumentando de forma muito significativa, e consequentemente o número de matrículas tem aumentado dentro da mesma proporção. Conforme o Censo Escolar da 
Educação Superior (BRASIL, 2015), naquele ano o país possuía 621 cursos de Licenciatura nas IES públicas e privadas. Já, no ano de 2019, o número de cursos sofreu um aumento de aproximadamente 50,12\%, passando para 1245. De acordo com Wachowicz (2013), nos últimos anos as IES vêm implantando um processo muito acentuado de interiorização de cursos pelo país. Pessoas que residem em locais remotos, até há pouco tempo, nem imaginavam que pudessem desfrutar da presença de uma IES, e que pudessem realizar o desejo de fazer um curso superior.

Atualmente, com a modalidade de EAD, os cursos superiores estão presentes em locais mais distantes dos grandes centros. Nesse caso, com a interiorização, verifica-se que os cursos de Licenciatura têm acompanhado esta interiorização, e têm passado por um processo muito acentuado de aumento de vagas, o que implica imediatamente em número de matrículas. A cada dia é mais frequente o número de estudantes que tem buscado, em cursos de Licenciatura em EAD, uma oportunidade de colocação profissional.

Com relação ao número de matrículas, nos cursos de Licenciatura em instituições publicas e privadas na modalidade de EAD entre os anos de 2015 e 2020, os dados emitidos pelos Censos Escolares (BRASIL, 2015; 2019) mostram que as IES privadas experimentaram um crescimento muito mais acentuado do que as IES públicas, pois enquanto estas tinham, no ano de 2015, 307 alunos matriculados, aquelas contabilizavam 621. No ano de 2020, o número de alunos matriculados sofreu um salto muito significativo nas IES privadas, que contabilizavam 843 matriculas, contra 402 nas IES públicas, um aumento de aproximadamente $63,58 \%$, dentro de um período de 5 anos.

De acordo com Gatti e Barreto (2009), a formação de professores no Brasil, para as gerações futuras, está com uma forte tendência direcionada aos cursos oferecidos pela modalidade da EAD e na rede privada de ensino. Além de se preocupar com a formação profissional dos futuros candidatos a professor, as autoras mantêm preocupação com a expansão desordenada que vem sendo implementada nos cursos de Licenciatura em EAD em todo o país. As posições de Gatti e Barreto (2009) estão se concretizando, pois de acordo com dados fornecidos pelo Censo Escolar (BRASIL,2019), os cursos de formação de professores em EAD experimentaram um crescimento de 10,4\% no número de matrículas entre os anos de 2018 e 2019, enquanto os mesmos cursos no modelo presencial tiveram uma redução de $2,92 \%$ no mesmo período de tempo. Este resultado mostra que está se configurando uma tendência no aumento do número de professores formados na modalidade da EAD. 


\section{O CRESCIMENTO DO NÚMERO DE MATRÍCULAS E DE POLOS NOS CURSOS DE LICENCIATURA NA MODALIDADE DA EAD}

No período recortado, entre 2015 e 2019, os cursos de Licenciatura na modalidade de EAD sofreram uma variação bastante acentuada quanto ao número de matrículas. De um lado, mesmo nas IES públicas em que o crescimento normalmente se apresenta mais tímido, verificase que houve uma expansão no número de alunos matriculados. Por outro lado, foi nas IES privadas que o número de matrículas sofreu um crescimento mais acentuado. A Tabela 1, a seguir, apresenta a variação no número de matrículas, nos cursos de Licenciatura, no período de 2015 a 2019 nos cursos de Licenciatura nas IES públicas e privadas no Brasil.

Tabela 1 - Matrículas nas IES Públicas e Privadas nos Cursos de Licenciatura

\begin{tabular}{c|c|c|c|c|c}
\hline Ano & $\begin{array}{c}\text { Matrícula } \\
\text { Licenciatura } \\
\text { EAD }\end{array}$ & Pública & \% & Privada & \% \\
\hline 2015 & 563.551 & 86.802 & 15,4 & 476.749 & 84,59 \\
\hline 2016 & 641.580 & 81.881 & 12,76 & 559.699 & 87,23 \\
\hline 2017 & 745.611 & 110.145 & 14,7 & 635.466 & 85,22 \\
\hline 2018 & 817.910 & 113.767 & 13,9 & 704.143 & 86,10 \\
\hline 2019 & 903.288 & 105.790 & 11,7 & 797.498 & 88,28 \\
\hline
\end{tabular}

Fonte: Elaborada pelo autor com base em dados do MEC.

Com base nos dados apresentados na Tabela 1, verifica-se que o número de matrículas nos cursos de Licenciatura, tanto nas IES públicas quanto nas privadas tem experimentado crescimento bastante significativo de um ano para outro. De acordo com Censo Escolar (BRASIL, 2018), as IES privadas vêm passando por um período de expansão e interiorização bastante significativo nos últimos anos, e este fato tem contribuído bastante para o aumento no número de matrículas nos cursos de Licenciatura. Nas IES públicas, nos cursos de Licenciatura na modalidade de EAD, o número de matrículas sofreu um pequeno aumento em seus valores ao longo dos anos; no entanto, a porcentagem de alunos matriculados tem diminuído a cada ano.

Este fato vem comprovar o que foi dito por Gatti e Barreto (2009), de que num futuro próximo os cursos de Licenciatura estariam, em sua totalidade, sendo realizados em sua maioria nas IES privadas e na modalidade da EAD. As mesmas autoras comentam que este fato é preocupante, pois algumas IES privadas não possuem sequer uma estrutura adequada para o provimento de cursos na modalidade presencial, e para disponibilizar tais cursos na modalidade da EAD necessitam, obrigatoriamente, melhorar a estrutura da instituição. Neste caso a 
formação destes alunos fica comprometida, influenciando na qualidade dos futuros profissionais da educação.

De acordo com o Censo Escolar (BRASIL, 2019), o aumento do número de matrículas tem ocorrido principalmente pela expansão do número de polos implantados pelo interior do país. Nos últimos anos, as IES privadas vêm implantando um rigoroso processo de interiorização de polos, e isto tem levado oportunidade de estudos para pessoas nas mais variadas localidades. Com esta expansão e interiorização de polos, o que se nota é que o número de matrículas tem aumentado dentro das mesmas proporções.

Com relação às IES públicas, o que se verifica é que a expansão de seus polos tem ocorrido de maneira bem mais tímida, devido à falta de investimento para instalação e manutenção. A Tabela 2, a seguir, apresenta a variação no número de polos dos cursos de Licenciatura dentro do período analisado.

Tabela 2 - Número de Polos nas IES Públicas e Privadas

\begin{tabular}{c|c|c|c|c|c}
\hline Ano & $\begin{array}{c}\text { Número } \\
\text { de Polos }\end{array}$ & Pública & $\%$ & Privado & $\%$ \\
\hline 2015 & 4.915 & 1.281 & 26,05 & 3.634 & 73,93 \\
\hline 2016 & 5.133 & 1.266 & 24,66 & 3.867 & 75,33 \\
\hline 2017 & 7.050 & 1.394 & 19,72 & 5.656 & 80,22 \\
\hline 2018 & 12.112 & 1.802 & 14,87 & 10.310 & 85,12 \\
\hline 2019 & 16.135 & 1.933 & 11,9 & 14.202 & 88,01 \\
\hline
\end{tabular}

Fonte: Elaborada pelo autor com base em MEC.

Analisando os dados apresentados pela Tabela 2, constata-se que o número de polos, nas IES no Brasil, sofreu uma variação muito acentuada nos últimos 2 anos. Nas IES públicas, percentualmente, o número de polos foi reduzido, enquanto nas IES privadas, a porcentagem no número de polos vem aumentando de forma acentuada. Este resultado apenas confirma os dados emitidos pelo MEC (BRASIL, 2020), no qual se encontra que o aumento no número de polos vem ocorrendo devido à enorme expansão e interiorização implantada pelas IES privadas em todas as regiões do país.

Realizando-se um comparativo entre os dados apresentados pelas Tabelas 1 e 2, nota-se que enquanto, de um lado, nas IES públicas o número de matrículas sofreu um aumento de $21,87 \%$, no período analisado, o número de polos experimentou um crescimento de 50,89\% no mesmo período. Por outro lado, nas IES privadas, enquanto o número de matrículas teve um aumento de $67,27 \%$, o número de polos sofreu uma variação de $290,8 \%$ dentro do período. 
O Gráfico 1 apresenta as linhas de comparação entre a porcentagem do número de matrículas versus a porcentagem do número de polos, para os cursos de Licenciatura nas IES públicas e privadas dentro do período analisado:

Gráfico 1 - Porcentagem de Matrícula x Porcentagem de Polos nas Licenciaturas da EAD

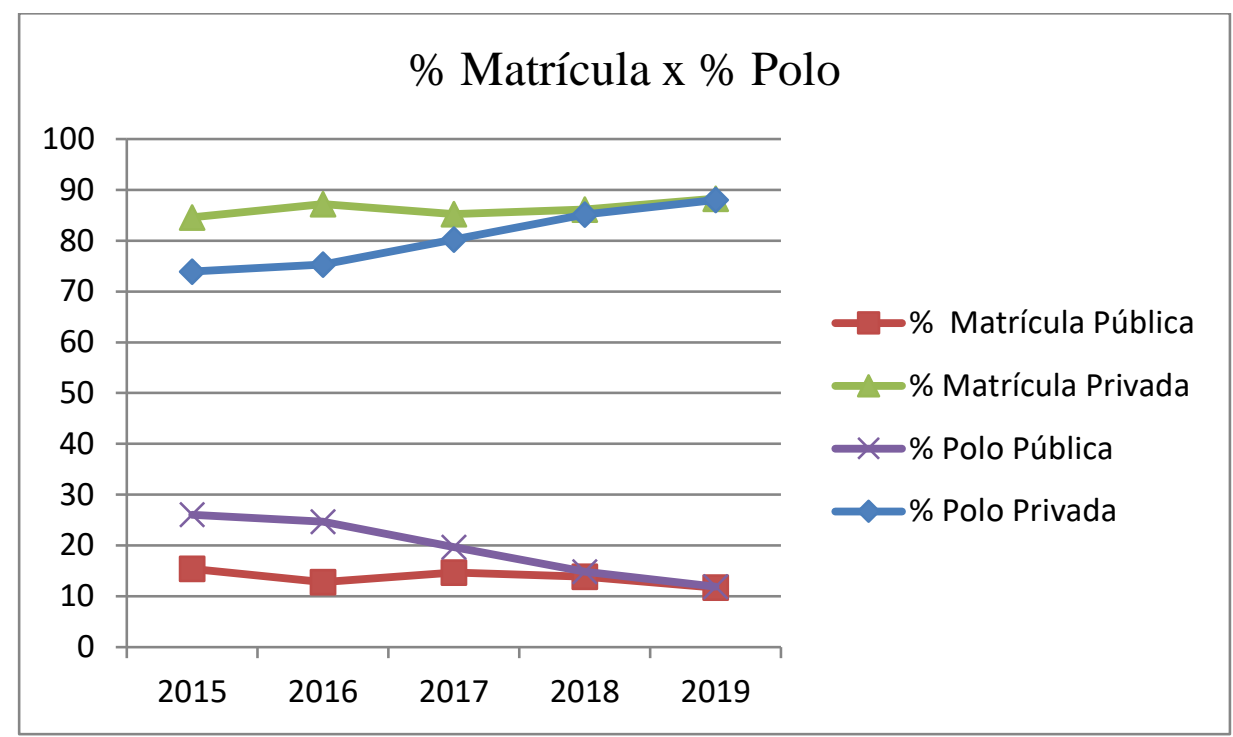

Fonte: Elaborado pelo autor com base em dados do MEC.

Por meio dos dados apresentados pelo Gráfico 1, pode-se concluir que a expansão do número de matrículas nos cursos de Licenciatura em EAD nas IES privadas, está diretamente ligada ao aumento significativo no número de polos, pois, à medida que a quantidade de polos aumenta, o número de matrículas acompanha na mesma proporção. Com relação aos cursos de Licenciatura nas IES públicas, nota-se que a porcentagem no número de polos tem diminuído bastante, e o número de matrículas tem apresentado uma queda modesta, mas bastante significativa. Neste caso o que se verifica é que o número de matrículas não tem aumentado sem o crescimento no número de polos.

\section{CONSIDERAÇÕES FINAIS}

As reflexões apresentadas neste artigo mostram os desafios evidenciados nos cursos de Licenciatura ofertados na Educação a distância, pública e privada. A modalidade da EAD ainda está em desenvolvimento no país, mas o seu amadurecimento poderá ser o caminho para que, num futuro próximo, mais brasileiros possam ter acesso à educação superior.

O Brasil é um país que apresenta muitas desigualdades econômicas e sociais, e o número de oportunidades na educação têm sido muito escassas. A democratização da educação tem 
como função tornar mais acessível, expandir e interiorizar as oportunidades de acesso. Nesse caso, a EAD apresenta uma função muito importante, pois pode alcançar regiões altamente remotas com baixo custo de implantação. Nesse sentido, as IES têm buscado a interiorização de seus cursos, principalmente as privadas, que vêm implementando um processo de democratização da educação em todas as regiões do país. Nessa direção, a expansão do número de polos tem sido fundamental para aumentar o número de matrículas de alunos nos cursos superiores.

Os dados apresentados nesse artigo mostram que a oferta de cursos de Licenciaturas passa obrigatoriamente pela expansão do número de polos. Isso ficou bem evidente nos resultados apresentados para as IES públicas, e principalmente para as privadas. $\mathrm{O}$ aumento do número de Polos tem ocasionado uma expansão muito significativa quanto ao número de matrículas, para os cursos de Licenciatura, nas IES privadas. Em contrapartida, nas IES públicas o mesmo movimento não foi verificado, pois a porcentagem do número de polos tem diminuído nos últimos anos, e o número de matrículas sofrendo pequenas quedas. Através desses dados, pode se concluir que o processo de interiorização, expansão e democratização da Educação passa, obrigatoriamente, pela EAD e, em particular, pela interiorização do número de polos.

Por fim, se essa tendência continuar, os cursos de Licenciatura em EAD, em sua maioria, tendem a ser oferecidos pelas IES privadas, devido à financeirização que vem sendo implementada com o aumento do número de polos.

\section{REFERÊNCIAS}

ALVES, João Roberto Moreira. A História da EaD no Brasil. In: LITTO, Fredric Michael; FORMIGA, Manuel Marcos Maciel (Orgs.). Educação a distância: o estado da arte. São Paulo: Pearson Education do Brasil, 2009.

BARRETO, Patrícia Menna. Custo-aluno na Educação a Distância: uma análise a partir de um projeto de implantação em uma IES privada no RS, 2018. Monografia (Bacharelado em Ciências Contábeis) - Universidade Federal do Rio Grande do Sul, 2018. Disponível em: https://www.lume.ufrgs.br/handle/10183/187605. Acesso em: 12 mar.2021.

BRASIL. Decreto Lei $\mathrm{n}^{\circ}$ 5.622, de 19 de dezembro de 2005. Regulamenta o artigo 80 da Lei $\mathrm{n}^{\circ}$ 9.394, de 20 de dezembro de 1996, que estabelece as diretrizes e bases da educação nacional. Brasília, DF, 2005. Disponível em: http://portal.mec.gov.br/seed/arquivos/pdf/dec_5622.pdf. Acesso em: 10 out. 2020.

BRASIL. Censos Escolares da Educação Superior/ Sinopses Estatísticas da Educação Superior - 2015. Brasília, DF: Ministério da Educação/Instituto Nacional de Estudos e Pesquisas Educacionais Anísio Teixeira. Disponíveis em: http://inep.gov.br/sinopsesestatisticas-da-educacao-superior. Acesso em: 15 set. 2020. 
BRASIL. Censos Escolares da Educação Superior/ Sinopses Estatísticas da Educação Superior - 2018, 2019. Brasília, DF: Ministério da Educação/Instituto Nacional de Estudos e Pesquisas Educacionais Anísio Teixeira. Disponíveis em: http://inep.gov.br/sinopsesestatisticas-da-educacao-superior. Acesso em: 15 set. 2020.

BRASIL. Ministério da Educação e Cultura. Universidade Aberta do Brasil (UAB). 2018a, Disponível em: http://portal.mec.gov.br/busca-geral/248-programas-e-acoes-1921564125/uabuniversidade-aberta-do-brasil-382561829/12265-universidade-aberta-do-brasil-uab. Acesso em: 20 ago. 2020.

BRASIL. Ministério da Educação e Cultura. Secretaria de Educação a Distância. Referenciais de qualidade para educação superior a distância, Brasília, 2007, Disponível em: http://portal.mec.gov.br/proinfo/193-secretarias-112877938/seed-educacao-a-distancia96734370/12777-referenciais-de-qualidade-para-ead. Acesso em: 20 ago. 2020.

BRASIL. Decreto Lei $n^{o} 5.800$, de 08 de junho de 2006. Dispõe sobre o Sistema Universidade Aberta do Brasil (UAB), Brasília, DF, 2006. Disponível em: https://uab.ufsc.br/files/2008/07/3_decreto_5800.pdf. Acesso em: 20 ago. 2020.

BRASIL. Ministério da Educação e Cultura. Brasília, O que é um polo de educação a distância, 2020. Disponível em: http://portal.mec.gov.br/pradime/355-perguntas-frequentes911936531/educação-a-distancia-1651636927/12824-o-que-e-um-polo-deeducacao-adistancia. Acesso em: 20 ago. 2020.

CARMO, Hermano. Ensino superior a distância, v. I e II. Lisboa: Universidade Aberta, 1997.

GATTI, Bernadete Angelina (Coord.); BARRETO, Elba Siqueira de Sá. Professores do Brasil: impasses e desafios. Brasília/DF: UNESCO, 2009.

GIOLO, Júlio. A educação à distância e a formação de professores. Educação \& Sociedade, v.29, n. 105, p. 1211-1234, Campinas, set/dez., 2008.

LITWIN, Edith. Educação a Distância: temas para o debate de uma nova agenda educativa. Porto Alegre: Artmed, 2001.

MAIA, Carmem. MATTAR, João. ABC da EaD: a Educação a Distância hoje. São Paulo: Pearson, 2007.

MOTA, Ronaldo. A Universidade Aberta do Brasil. In: LITTO, Fredric Michael; FORMIGA, Manuel Marcos Maciel (Orgs.). Educação a distância: o estado da arte. São Paulo: Pearson Education do Brasil, 2009.

NUNES, Ivônio Barros. Noções de Educação a Distância, Revista Educação a Distância, v.4, n. 5, p. 7-25, dez./93-abr./94, Brasília, INED, 1994. Disponível em: http://www.educadores.diaadia.pr.gov.br/arquivos/File/2010/artigos teses/EAD/NOCOESEA D.PDF. Acesso em 1 mar. 2021.

WACHOWICZ, Marcos. Ensino a distância e direitos autorais: a produção do conhecimento e a sua tutela jurídica. In: FIDALGO, Fernando Selmar Rocha, et al. (Org.). Educação a distância: meios, atores e processos. Belo Horizonte: CAED-UFMG, 2013. 


\section{SOBRE OS AUTORES}

Henaldo Barros Moraes é doutorando em Educação pela Universidade de Uberaba, MG. Tem mestrado em Redes de Computadores pela Faculdade de Engenharia Elétrica da Universidade Federal de Uberlândia (UFU). Docente do Centro Universitário de Patos de Minas (UNIPAM).

E-mail: henaldobarros@gmail.com

ORCID: https://orcid.org/0000-0002-1279-2469

José Carlos Souza Araújo é Doutor em Educação na área de Filosofia e História da Educação, pela Universidade Estadual de Campinas (UNICAMP), Mestre em História Social pela Universidade de São Paulo (USP), licenciado em História pela Pontifícia Universidade Católica de Campinas, cursou Filosofia pelo Instituto Estigmatino de Campinas, e é bacharel em Teologia pela Faculdade de Teologia Nossa Senhora da Assunção, São Paulo, SP. É docente do Programa de Pós-graduação em Educação da Universidade de Uberaba (UNIUBE). Professor aposentado da Universidade Federal de Uberlândia (UFU).

E-mail: jcaraujo.ufu@gmail.com

ORCID: https://orcid.org/0000-0002-7972-8875 